\title{
Calf management risk factors on dairy farms associated with male calf mortality on veal farms
}

\author{
D. L. Renaud, D. F. Kelton, S. J. LeBlanc, D. B. Haley, and T. F. Duffield ${ }^{1}$ \\ Department of Population Medicine, University of Guelph, Ontario, N1G 2W1, Canada
}

\section{ABSTRACT}

The objective of this cross-sectional herd-level study was to assess the association of calf management practices on source dairy farms with mortality risk on veal farms. From April to October 2016, 52 source dairy farms supplying male calves to 2 veal operations were visited once. A questionnaire was administered that covered all areas of calf management, calves between 1 and $10 \mathrm{~d}$ of age were examined using a standardized health scoring system, and blood was taken to evaluate passive transfer of immunoglobulins. The mortality risk for calves from each dairy farm was calculated based on the number of male calves sold from the dairy farm and that died during 2016 at the veal operations. The mean mortality risk was calculated for both veal farms and, based on the veal facility-adjusted mortality risk, dairy farms were classified as high- or low-mortality source farms. Using the information gathered at the 52 source dairy farms, a logistic regression model was used to assess factors associated with being a high-mortality source farm. Suppliers to veal farm 1 had a mean mortality risk of $9.6 \%$ and suppliers to veal farm 2 had a mean mortality risk of $4.2 \%$. The lower mortality risk at veal farm 2 was partially influenced by a shorter period of observation. Of the 182 calves examined during the single visit to the source dairy farms, $41 \%$ of male calves and $29 \%$ of female calves had at least one identifiable health abnormality. The risk of failure of passive transfer on source dairy farms was low, with only $13 \%$ of calves tested having $<10 \mathrm{mg}$ of $\mathrm{IgG} / \mathrm{mL}$ of serum. The subset of calves examined at the source dairy farm was not followed prospectively to the veal farms. Using a tube feeder or pail to feed colostrum, bedding male calves on wood shavings or chopped straw at the source dairy farm, and the herd veterinarian not routinely and actively inquiring about the health and performance of calves during regular herd visits were significantly associated with the farm being classified as a highmortality source dairy farm. Checking the calving pen

Received July 26, 2017.

Accepted October 17, 2017.

${ }^{1}$ Corresponding author: tduffiel@uoguelph.ca at an interval of every $3 \mathrm{~h}$ or more during the day was associated with a lower probability of being classified as a high-mortality source dairy farm. The results of this study suggest that there are management practices on the source farm that contribute to the risk of mortality on veal farms.

Key words: mortality, veal farm, dairy, management practices

\section{INTRODUCTION}

Management of the newborn dairy calf is essential to its survival and productivity. Calving management, colostrum management, feeding, housing, and timely treatment on dairy farms are critical to the calf, including male calves. Male calves transferred to veal farms often face disease challenges resulting from transportation stress (Mormede et al., 1982), commingling with calves from multiple sources (van der Fels-Klerx et al., 2000), placement into a new housing facility, and adapting to a new diet, all within the first 2 wk of life. Currently, high levels of mortality (Bähler et al., 2012; Pardon et al., 2012a), morbidity (Pardon et al., 2012a), antimicrobial use (Pardon et al., 2012b; Bos et al., 2013), and antimicrobial resistance (Catry et al., 2016) are challenges faced in the veal industry. With an increased focus on improving animal welfare and increased pressure to reduce antimicrobial use (Pardon et al., 2014), emphasis needs to be placed on prevention of disease. Many areas could be explored for disease prevention but as most mortality occurs in the first 21 d on the veal farm (Bähler et al., 2012; Pardon et al., 2012a; Winder et al., 2016), calf management on the source dairy farm may play a role. Currently, there is a lack of peer-reviewed literature identifying management factors on dairy farms that affect calf health at veal farms even though many veal producers are empirically able to identify high-mortality source dairy farms.

Because male calves are more likely to experience dystocia (Olson et al., 2009) and with approximately $10 \%$ of calvings resulting in dystocia (Mee, 2008), it is imperative to have appropriate timing and methods of intervention through regular surveillance (Mee, 2004) to reduce many of the effects associated with dystocia. 
Successful passive transfer of immunity is essential for calves in the prevention of disease (Postema and Mol, 1984; Pardon et al., 2015). To achieve adequate passive transfer of immunoglobulins, it is necessary to provide an adequate quantity of high-quality colostrum quickly after birth while minimizing bacterial contamination (Godden, 2008). Despite its known importance, failure of passive transfer is estimated to affect 41 to $43 \%$ of male dairy calves (Wilson et al., 2000; Pardon et al., 2015). A few studies have described some discrimination against male calves in regard to colostrum management, with male calves being more likely to be fed colostrum contaminated with bacteria (Fecteau et al., 2002), receive a smaller volume of colostrum, have delayed colostrum feeding, or be left with the dam as a mechanism to feed colostrum (Shively et al., 2016). Given the role that colostrum management has been demonstrated to play in disease prevention (Wells et al., 1996; Donovan et al., 1998; Windeyer et al., 2014) but also in improved rate of gain and feed efficiency in female dairy calves (Robison et al., 1988; Faber et al., 2005), reasons for this discriminatory behavior and its effect on male calf mortality need to be described.

Several studies have shown the importance of early life nutrition. Nutritional programs providing higher volumes of milk have shown increased weight gain and may aid in improving disease resistance (Khan et al., 2007; Ollivett et al., 2012; Todd et al., 2017). As a lower weight at arrival at a veal facility has been associated with greater risk of mortality (Brscic et al., 2012; Winder et al., 2016), nutrition might be an important factor in prevention of morbidity and mortality in male calves.

Housing style (Waltner-Toews et al., 1986), ventilation (Windeyer et al., 2014), and bedding type (Lago et al., 2006) have been shown to be associated with female dairy calf mortality. The effect of housing for male calves on the source farm on health in veal operations is largely unknown.

The objective of this cross-sectional herd-level study was to assess the association of calf management practices on source dairy farms with mortality risk on veal farms. A secondary objective was to identify management differences between male and female dairy calves at the source dairy farms.

\section{MATERIALS AND METHODS}

\section{Experimental Design}

A cross-sectional study was conducted from April to October 2016 to collect data on calf management practices at source dairy farms supplying calves to 2 veal facilities in Ontario, Canada. The 2 veal operations were selected due to their proximity to the University of Guelph and willingness to participate in this study. Veal farm 1 is a milk-fed veal facility that uses group and individual to group housing. This farm ships calves to slaughter for white veal after a production period of approximately $20 \mathrm{wk}$ and had a mean hot carcass weight of $280 \mathrm{lb}(127 \mathrm{~kg})$ for all calves slaughtered in 2016. Veal farm 2 is a grain-fed veal facility that uses individual to group housing for all calves reared. After 11 wk at veal farm 2, the calves are shipped to a group housing facility and are slaughtered after an additional 20 wk for red veal. The mean hot carcass weight was $380 \mathrm{lb}(172 \mathrm{~kg})$ for all calves slaughtered in 2016 from veal farm 2. Both veal facilities maintained housing facilities at a minimum of $15^{\circ} \mathrm{C}$ in the initial portion of the growing period and housed the calves on a slatted floor.

The source dairy farms were visited once and each visit involved the completion of a questionnaire, examination of calves between 1 and $10 \mathrm{~d}$ of age using a standardized health scoring system, and collection of blood to evaluate passive transfer. The questionnaire (Supplemental Data; https://doi.org/10.3168/ jds.2017-13578) comprised 75 questions addressing herd demographics, calving management, newborn calf care, colostrum management, calf housing and feeding, dry cow management, and veterinary assistance. The questionnaire was developed through a literature review of the main factors affecting calf health and based on questions developed by Vasseur et al. (2010). All questions were asked verbally of each participating dairy producer and their responses were entered into an online platform (Qualtrics; https://www.qualtrics .com/) by one of the investigators during the visit. The questionnaire specifically inquired about differences in male and female calf management. The standardized health screening was completed using the Calf Health Scorer application developed by the University of Wisconsin (https://www.vetmed.wisc.edu/dms/ fapm/apps/chs.htm). This application uses validated methods for fecal scoring (McGuirk, 2008), respiratory screening (McGuirk and Peek, 2014), and navel inflammation (adapted from Fecteau et al., 1997). Following the health examination, approximately $10 \mathrm{~mL}$ of whole blood was collected from the jugular vein into a sterile blood collection tube without an anticoagulant (BD Vacutainer; Becton, Dickinson and Co., Franklin Lakes, NJ). Blood samples were allowed to clot and then centrifuged at $1,500 \times g$ for $15 \mathrm{~min}$ at approximately $20^{\circ} \mathrm{C}$. Serum was separated and stored at $-20^{\circ} \mathrm{C}$ until submission to the Saskatoon Colostrum Company (Saskatoon, SK, Canada) for analysis of serum IgG by radial immunodiffusion as described by Chelack et al. (1993). Calves were classified as having failure of pas- 


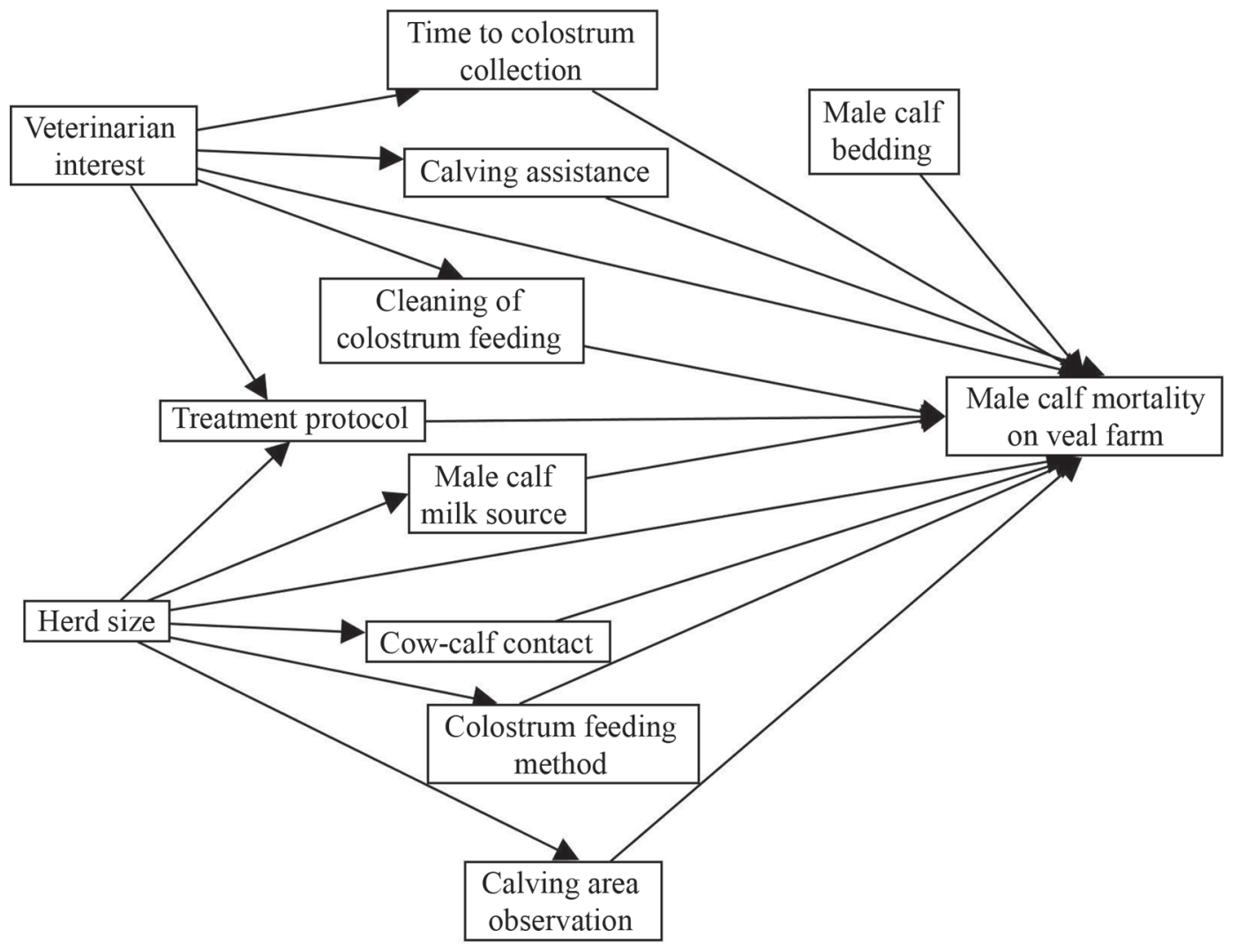

Figure 1. Causal diagram describing the relationship of measured variables to high-mortality source dairy farms.

sive transfer (FPT) if their serum IgG was $<10 \mathrm{~g} / \mathrm{L}$ (Godden, 2008). The subset of calves examined at the source dairy farm was not followed prospectively to the veal farms.

Human ethics (REB\#16MR023) and animal use (AUP\#3453) approvals were received from the University of Guelph before beginning the on-farm portion of the study.

Dairy producers who sold more than 5 male calves in 2015 to veal farm 1 or veal farm 2 were eligible for participation in the study. The participants were contacted by telephone and provided with information regarding the purpose and terms of participation in the project. After receiving consent from the dairy producer, an onfarm visit was conducted. To ensure that confidentiality was maintained, a unique anonymous code was assigned to each producer following the on-farm visit. For those who declined to participant, no information was made available to compare responders to nonresponders.

\section{Statistical Analysis}

All statistical analyses were conducted using Stata 14 (StataCorp LLC, College Station, TX). Data were imported into Stata 14 from Excel (Microsoft Corp., Redmond, WA) and checked for completeness. A causal diagram (Figure 1) was created to evaluate the relationships between the potential explanatory variables and the outcomes of interest. Descriptive statistics were generated for all explanatory variables in the data set. For questions that specifically inquired about differences between male and female calf management practices, a 2-sample z-test was performed to compare proportions.

A facility-adjusted mortality risk was calculated for each veal farm based on the total number of calves that were received and died in 2016 during the rearing periods of $20 \mathrm{wk}$ and $11 \mathrm{wk}$ for veal farms 1 and 2, respectively. A mortality risk was also calculated for each source dairy farm based on the number of male calves sold and the number that died in 2016 at the veal operations. Based on the 2016 facility-adjusted mortality risk, source dairy farms were classified as high- (HMSF) or low- (LMSF) mortality source farms. A source dairy farm was classified as an HMSF if the farm mortality risk was greater than the facilityadjusted mortality risk of the veal farm to which the source dairy farm shipped male calves. A source dairy 
farm was a LMSF if the farm mortality risk was lower than the veal facility-adjusted mortality risk.

One explanatory logistic regression model was created to identify characteristics of the HMSF versus LMSF, and one explanatory Poisson regression model was built to explore herd-level factors associated with rate of FPT at each source dairy farm visited using the blood collected from the calves during the single farm visit. The logistic model assumption of linearity of continuous variables was assessed by plotting the logarithmic odds of the outcome against the variable, whereas the assumption of linearity in the Poisson model was tested by plotting the natural logarithm of the outcome against the continuous variable. If a variable failed to meet the linearity assumption, the variable was categorized. In the logistic model, calving observation during the day, cow-to-calf contact after calving, and time to collect colostrum after calving were dichotomized at the median response. Herd size was categorized into quartiles in both the Poisson and logistic models. Collinearity among the explanatory variables was tested using Spearman rank coefficients. If the correlation coefficient between 2 variables was $\geq 0.7$, only one variable was retained based on fewest missing values, reliability of measurement, and biological plausibility. Univariable logistic regression models were constructed to screen for variables that were unconditionally associated with the outcome using a $P$-value of 0.2 . Risk factors that had univariate associations $(P<0.2)$ were subsequently offered to a multivariable model through a manual forward stepwise process. Confounding was assessed by evaluating the effect of removing variables on the coefficients of the remaining variables. A variable was deemed a confounder if it was not an intervening variable based on the causal diagram and the log odds of a significant variable in the model changed by at least $20 \%$ when the potential confounder was added to the model. Two-way interactions were evaluated between variables suspected to interact based on evidence from the literature and remained in the final models if significant $(P$-value $<0.05$; Dohoo et al., 2010a). The logistic and Poisson model fit was assessed using Pearson and deviance $\chi^{2}$ tests. These tests were used in the logistic model because solely binomial data (i.e., leading the number of covariate patterns to be much lower than the number of data points in the data set) were included in the model (Dohoo et al., 2010b). Outliers were identified and evaluated using Pearson residuals and deviance residuals in both models. Additionally, in the logistic model, delta-betas, delta- $\chi^{2}$, and delta-deviance were explored, whereas, in the Poisson model, Anscombe residuals and Cook's distance were evaluated. If outliers were found, they were explored to determine the characteristics of the observations that made them outliers and ensure that data were not erroneous.

\section{RESULTS}

\section{Herd Demographics}

In total, 73 and 63 source dairy farms selling calves to veal farms 1 and 2, respectively, were contacted to participate in the study. Of those contacted, $23(32 \%)$ source dairy farms supplying veal farm 1 and 29 (46\%) source dairy farms supplying veal farm 2 agreed to participate. The participating source dairy farms had an average of 135 lactating cows, which is larger than the average Canadian herd size of 72 lactating cows (Canadian Dairy Information Center, 2016). The housing style used by participants was also different from Canadian dairy farms (Canadian Dairy Information Center, 2016): the majority milked the cows in freestall barns $(73 \%)$ and the remainder used tie-stall $(25 \%)$ or bedded packs $(2 \%)$ for housing.

\section{Calving Management and Newborn Calf Care}

Most participants (69\%) used group calving pens, with an average of $92 \%$ of calvings occurring in the designated calving area. Only $12 \%$ of producers washed or disinfected the calving area between calvings, and $38 \%$ used the calving area for sick or lame cows. The producers checked the calving area on average every 3 and $6 \mathrm{~h}$ during the day and night, respectively. Twenty-nine percent of producers used calving monitoring equipment such as video cameras. Overall, $14 \%$ of producers assisted with all calvings, with 19\% assisting with all calvings if calving area observations were made every $\leq 2 \mathrm{~h}$ during the day or $8 \%$ if the calving area was observed every $\geq 3 \mathrm{~h}$ during the day. The majority, however, assisted with a calving only after checking and finding a problem (64\%) or when the cow was not progressing as expected (17\%). Producers assisted with an average of $37 \%$ of primiparous calvings and $25 \%$ of multiparous calvings.

Calf care provided for newborn calves is described in Table 1 and did not differ between male and female calves.

\section{Colostrum Management}

Colostrum was typically fed within the first $4 \mathrm{~h}$ of life, and an average of $3 \mathrm{~L}$ was fed to each calf. Very few respondents evaluated colostrum quality before feeding 
Table 1. Proportion $(\%)$ of source dairy farms $(n=52)$ performing calf care management practices for all calves

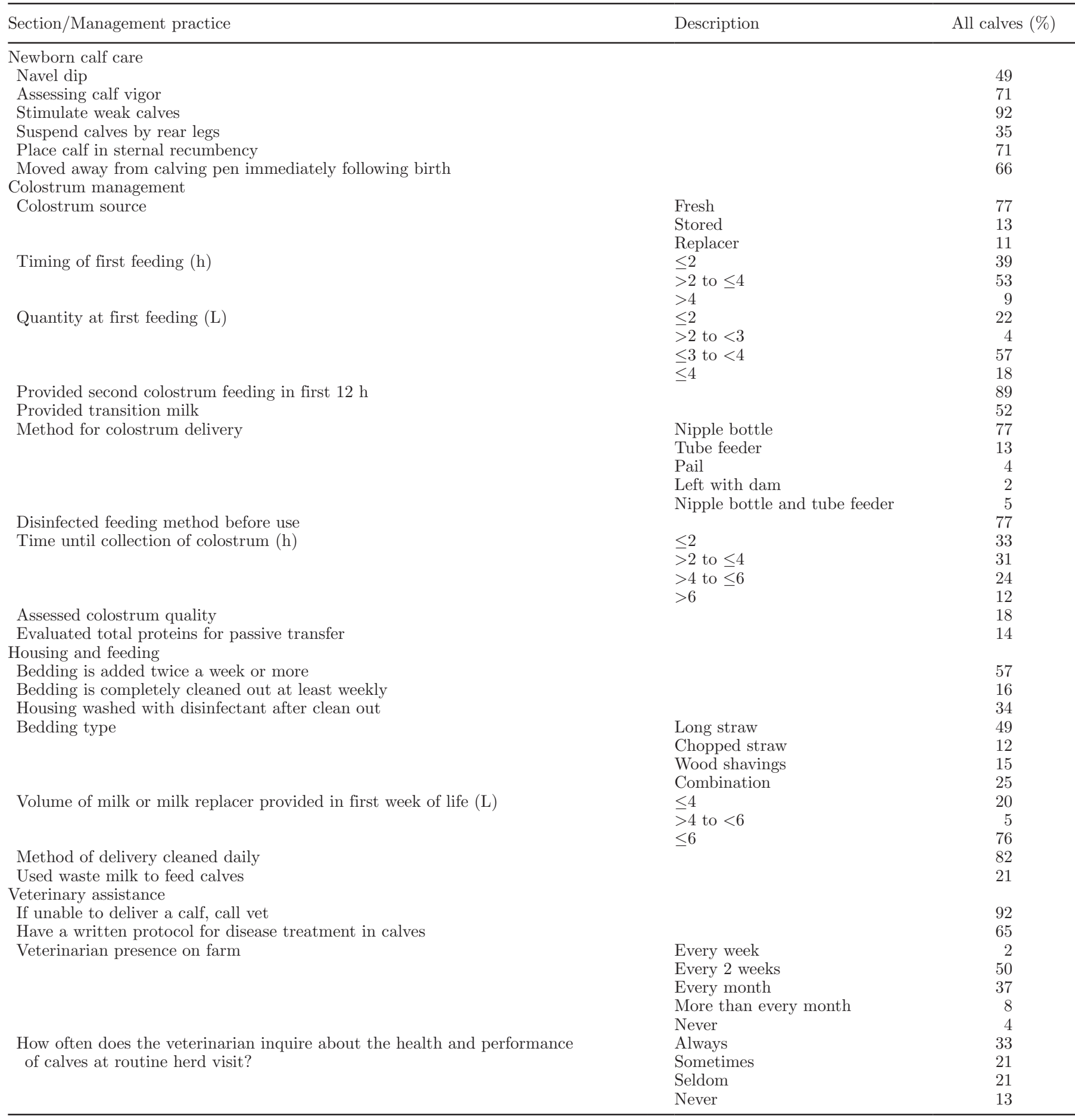

or tested serum total proteins to evaluate the success of the colostrum management program (Table 1).

\section{Housing and Feeding}

Male calves were more likely to be housed individually $(P=0.03)$, with $71 \%$ of source dairy farms hous- ing males individually and $54 \%$ of source dairy farms housing females individually. Bedding was added to the housing system at least twice a week and cleaned out more than every week on the majority of farms. The most commonly used bedding was long straw. Only $19 \%$ of farms kept male calves on the source dairy farm beyond $7 \mathrm{~d}$ of age. 
Most producers offered at least $6 \mathrm{~L}$ of milk or milk replacer to calves in the first week of life. Eighty-one percent of source dairy farms reported using solely a nipple bottle to deliver milk to male calves, whereas $33 \%$ solely used a nipple bottle for female calves $(P<$ $0.001)$. Source dairy farms were also less likely to use a robotic feeder to deliver milk to male calves $(P<$ 0.001 ), with only $8 \%$ using the feeder for male calves and $31 \%$ using the feeder for female calves. Most of the producers cleaned the feeding equipment daily and did not feed waste milk to calves (Table 1).

\section{Veterinary Assistance}

Most producers had a veterinarian on their farm at least every 2 wk for routine herd health visits. Farmers reported that most of the herd veterinarians did not routinely and actively inquire about the health and performance of dairy calves during regular herd visits (Table 1).

\section{Veal Farm Information}

Veal farm 1 received 8,028 calves in 2016 and 774 $(9.6 \%)$ died during the 20 -wk production period. A total of 23 source dairy farms for veal farm 1 were visited, with 11 source dairy farms being classified as HMSF. Veal farm 2 received 1,220 calves in 2016, of which 51 $(4.2 \%)$ died during the 11 -wk production period. A total of 29 source dairy farms for veal farm 2 were visited, with 8 being classified as HMSF. The source dairy farms shipped an average of 31 calves in 2016 (maximum of 94 and minimum of 5 calves).

\section{Individual Calf Examination and Passive Transfer}

A total of 182 calves, aged 1 to $10 \mathrm{~d}$, were examined during the source dairy farm visits, and FPT was found in $15 \%(\mathrm{n}=9)$ of male calves and $13 \%(\mathrm{n}=13)$ of female calves. The variables unconditionally associated with herd FPT rate were colostrum source fed, having a sufficient quantity of colostrum reserves, and always cleaning the colostrum feeding equipment before use. In the final model, colostrum source was the only remaining variable. If colostrum replacer was used as a principal colostrum source for calves, those herds had a higher incidence of FPT (incidence rate ratio: 2.98; 95\% CI: $1.12-7.93 ; P=0.03$ ) compared with using fresh colostrum as a principal colostrum source for calves.

An abnormal navel score, defined as $\geq 2$, was found in $33 \%(\mathrm{n}=21)$ and $7 \%(\mathrm{n}=7)$ of male and female calves, respectively. Overall, $41 \%(\mathrm{n}=26)$ of male calves and $29 \%$ of female calves had at least one identifiable health abnormality.

\section{High-Mortality Dairy Farms}

The variables unconditionally associated with being an HMSF are presented in Table 2. In the final multivariable model, 5 variables remained $(P<0.05$; Table 3 ). Using a tube feeder or pail to feed colostrum, having a herd veterinarian who inquired less frequently about the health and performance of calves, and using wood shavings or chopped straw as bedding for male calves were all associated with higher odds of the dairy farm being classified as an HMSF. Checking the calving pen at an interval of every $3 \mathrm{~h}$ or greater was associated with lower odds of being classified as an HMSF. The time to collect colostrum following calving was retained in the model because it changed the log-odds of the colostrum feeding method variable by greater than $20 \%$. Two outliers were identified that shared the same covariate pattern; however, they were retained in the final model because the magnitude and the direction of the coefficients did not change when they were removed.

\section{DISCUSSION}

This study identified certain management practices on source dairy farms that are associated with mortality risk on veal farms. The major limitation of this study was the small number of source dairy farms visited, which resulted in large odds ratios and confidence intervals. The sample size was limited due to the resources available and low response rate of the source dairy farms. We identified associations of variables on the source farms with mortality risk at the veal farm, but we did not prospectively follow individual calves from source through the veal facility, nor did we compare the mortality risk in male calves from the source dairy farms at the veal facilities to mortality risk in female calves or adult dairy cows at the source dairy farms. The inability to identify when changes in management practices occurred and determine if they were altered as a result of previous health challenges is another limitation to the study. Other unmeasured factors could have affected mortality occurring at the veal facilities, such as mixing, transportation, BW at arrival, and genetic breeding strategies that could be proxy measures for the associations found or may intervene or modify the effects of the source dairy farm risk factors. Despite these limitations, this study is the first to trace male calves back to source dairy farms; we identified the factors bedding type, frequency of monitoring the calving area, colostrum feeding method, and the herd veterinarian's interest in the health and performance of calves as being associated with HMSF.

The mortality risk calculated for veal farm 1 was substantially higher than that for veal farm 2. However, 
Table 2. Results of univariable logistic regression models evaluating risk factors for being a high-mortality source dairy farm from a single interview of 52 source dairy farms providing male calves to 2 veal farms

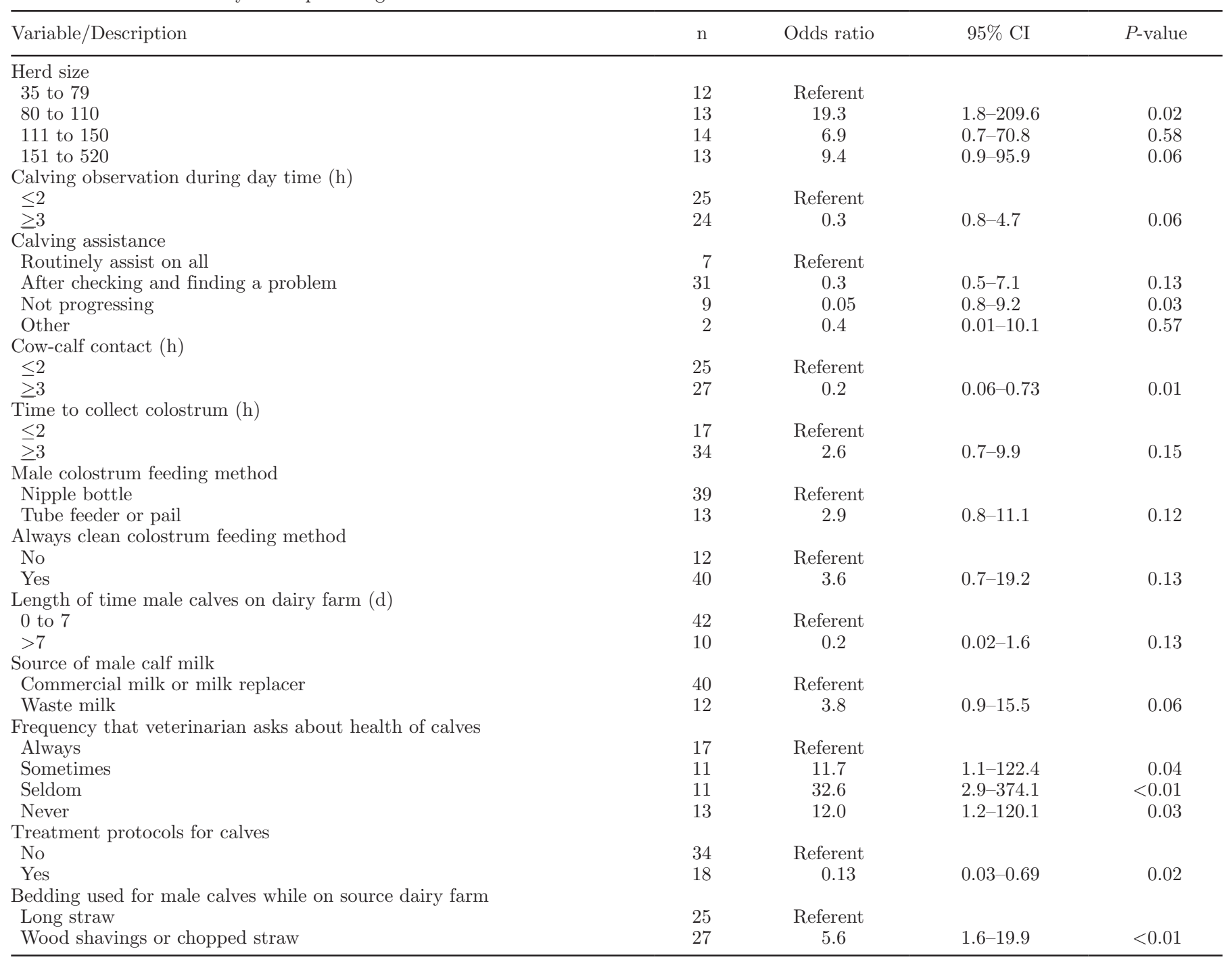

veal farm 2 had a shorter production period, which may have affected the mortality risk. Mortality risk at veal farm 1 was also higher than previously reported in Canadian studies (Sargeant et al., 1994; Winder et al., 2016) and international studies (Wilson et al., 2000; Bähler et al., 2012; Pardon et al., 2012a). As public concern surrounding animal welfare is increasing (Vanhonacker et al., 2008; Spooner et al., 2014), this level of mortality highlights the need to explore factors to improve animal health and welfare.

Monitoring the calving area less frequently during the day was associated with lower odds of being classified as an HMSF. It could be speculated that farms with more intensive monitoring of the calving area had higher levels of obstetrical assistance, which could be related to periparturient management decisions such as sire selection, excess nutrition leading to over-conditioning, and, for heifers, weight or size at breeding (Mee, 2008). Calves that are assisted during birth are less vigorous, have longer time to sternal recumbency, and had significantly higher levels of FPT (Barrier et al., 2012, 2013). As these factors have been associated with mortality (Schuijt and Taverne, 1994; Pardon et al., 2015), calving management may play a role in the prevention of mortality at veal operations.

Feeding colostrum other than by nipple bottle was associated with being an HMSF. When calves are fed using an esophageal tube feeder, the esophageal groove is not triggered, leading to the deposition of colostrum into the forestomachs (Lateur-Rowet and Breukink, 1983; Godden, 2008). As it takes additional time for the colostrum to transfer from the forestomachs into 


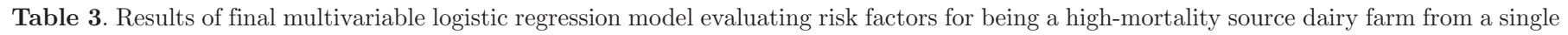
interview of 52 source dairy farms providing male calves to 2 veal farms

\begin{tabular}{|c|c|c|c|c|}
\hline Variable/Description & $\mathrm{n}$ & Odds ratio & $95 \% \mathrm{CI}$ & $P$-value \\
\hline \multicolumn{5}{|c|}{ Calving observation during day time (h) } \\
\hline$\leq 2$ & 25 & Referent & & \\
\hline$\geq 3$ & 24 & 0.02 & $0.0-0.7$ & 0.03 \\
\hline \multicolumn{5}{|c|}{ Time to collect colostrum after calving (h) } \\
\hline$\leq 2$ & 17 & Referent & & \\
\hline$\geq 3$ & 34 & 7.3 & $0.5-107.3$ & 0.15 \\
\hline \multicolumn{5}{|c|}{ Colostrum feeding method for male calves } \\
\hline Nipple bottle & 39 & Referent & & \\
\hline Tube feeder, pail or left with dam & 13 & 57.4 & $1.5-2,190$ & 0.03 \\
\hline \multicolumn{5}{|c|}{ Frequency that veterinarian asks about health of calves at routine herd visit } \\
\hline Always & 17 & Referent & & \\
\hline Sometimes & 11 & 222.4 & $3.2-1,522$ & 0.01 \\
\hline Seldom & 11 & 88.3 & $3.1-2,495$ & $<0.01$ \\
\hline Never & 13 & 416.8 & $6.2-2,770$ & $<0.01$ \\
\hline \multicolumn{5}{|c|}{ Bedding used for male calves while on source dairy farm } \\
\hline Long straw & 25 & Referent & & \\
\hline Wood shavings or chopped straw & 27 & 66.5 & $2.7-1,604$ & 0.01 \\
\hline
\end{tabular}

the small intestine, it may reduce the efficiency of colostrum absorption due to the closure of the gut (Bush and Staley, 1980). Although this challenge can be overcome with additional volume and appropriate timing (Godden et al., 2009; Elizondo-Salazar et al., 2011), the low volume of colostrum being fed by most producers could affect the level of FPT, increasing the level of mortality on the veal farm (Pardon et al., 2015).

The use of a commercial colostrum replacer by the source dairy farm was associated with a higher level of FPT in the calves tested at the single farm visit. This finding is similar to other studies, which demonstrated that calves fed colostrum replacer compared with fresh maternal colostrum had lower levels of IgG (Smith and Foster, 2007; Swan et al., 2007). Despite this finding, caution should be applied in the interpretation of this model due to the small number of calves evaluated, the reliance on survey data to indicate principal colostrum source for the herd, and the fact that this was not a primary objective of this study.

The type of bedding material is important in keeping calves clean, dry, and comfortable. The use of solely long straw bedding for male calves was associated with a dairy farm having lower odds of being classified as an HMSF. Long straw allows calves to adapt to cold or drafty conditions because deep nesting may preserve nutritional stores and immune function, leading to a reduction in the prevalence of respiratory disease (Lago et al., 2006). Our study took place during summer, but we expect that most farms used the same type of bedding for calves year round. Panivivat et al. (2004) demonstrated that calves housed on long straw had the fewest scour days and lower coliform counts in the bedding compared with calves on other bedding types. As respiratory disease and diarrhea are the main causes of mortality in veal calves (Bähler et al., 2012; Pardon et al., 2012a), the use of long straw bedding for male calves on dairy farms may help to reduce some of the mortality created by these diseases.

Many studies have demonstrated that producers view veterinarians as a reliable and credible source of information (Gunn et al., 2008; Jansen and Lam, 2012; Ritter et al., 2015). Veterinarians can initiate discussions and play a key role in implementing changes in management practices to improve disease control (Frank and Kaneene, 1993; Lam et al., 2011; Jansen and Lam, 2012). A surprising finding from this study was the low number of producers who reported that their veterinarian routinely and actively inquired about the health and performance of their calves. This variable was associated with a farm being an HMSF. Veterinarians need to engage in discussions with clients regarding calf health management to identify problems early and put in place corrective management practices as well as aid in therapeutic decision-making.

Very few differences were reported between the management of male and female calves. This differs from some other studies where male calves received different treatment than female calves (Fecteau et al., 2002; Shively et al., 2016; Renaud et al., 2017). Some level of information bias may have been present, where the respondents, knowing the purpose of the study, selectively suppressed differences in male and female calf management. Also, nonresponse bias, a form of selection bias, could have been related to the lack of differences found. However, this likely did not occur on all farms and highlights that most of the respondents visited did not manage male and female calves differently, except for the type of housing and method used to provide milk to the calves. 
Many calves had health abnormalities. Many male calves had an abnormal navel score, whereas the prevalence was lower in females, similar to that reported by Virtala et al. (1996). Navel infections may cause septicemia, leading to lower growth and increased mortality (Virtala et al., 1996; Donovan et al., 1998); thus, increased navel scores may play a role in mortality on veal farms.

\section{CONCLUSIONS}

Based on the results of this study, management practices occur on dairy farms that may affect subsequent male calf health on veal farms. The use of an esophageal tube feeder or pail to feed colostrum, using wood shavings or chopped straw as male calf bedding, infrequent inquiry by the herd veterinarian about the health and performance of calves, and observing the calving area more frequently were all associated with greater odds of the dairy farm being classified as having higher mortality in the veal operation.

\section{ACKNOWLEDGMENTS}

The authors thank all the participating producers. The first author was also supported by Grober Inc. (Cambridge, ON, Canada), Veal Farmers of Ontario (Guelph, ON, Canada), Dairy Farmers of Ontario (Mississauga, ON, Canada), the Ontario Ministry of Agriculture, Food and Rural Affairs, the Ontario Veterinary College (University of Guelph), and Mapleview Agri Ltd. (Palmerston, ON, Canada).

\section{REFERENCES}

Bähler, C., A. Steiner, A. Luginbühl, A. Ewy, H. Posthaus, D. Strabel, T. Kaufmann, and G. Regula. 2012. Risk factors for death and unwanted early slaughter in Swiss veal calves kept at a specific animal welfare standard. Res. Vet. Sci. 92:162-168. https://doi .org/10.1016/j.rvsc.2010.10.009.

Barrier, A., M. Haskell, S. Birch, A. Bagnall, D. Bell, J. Dickinson, A. Macrae, and C. Dwyer. 2013. The impact of dystocia on dairy calf health, welfare, performance and survival. Vet. J. 195:86-90. https://doi.org/10.1016/j.tvjl.2012.07.031.

Barrier, A., E. Ruelle, M. Haskell, and C. Dwyer. 2012. Effect of a difficult calving on the vigour of the calf, the onset of maternal behaviour, and some behavioural indicators of pain in the dam. Prev. Vet. Med. 103:248-256. https://doi.org/10.1016/j.prevetmed .2011.09.001.

Bos, M. E., F. J. Taverne, I. M. van Geijlswijk, J. W. Mouton, D. J. Mevius, and D. J. Heederik. 2013. Consumption of antimicrobials in pigs, veal calves, and broilers in the Netherlands: Quantitative results of nationwide collection of data in 2011. PLoS One 8:e77525. https://doi.org/10.1371/journal.pone.0077525.

Brscic, M., H. Leruste, L. Heutinck, E. Bokkers, M. Wolthuis-Fillerup, N. Stockhofe, F. Gottardo, B. Lensink, G. Cozzi, and C. V. Reenen. 2012. Prevalence of respiratory disorders in veal calves and potential risk factors. J. Dairy Sci. 95:2753-2764. https://doi.org/ 10.3168/jds.2011-4699.
Bush, L., and T. Staley. 1980. Absorption of colostral immunoglobulins in newborn calves. J. Dairy Sci. 63:672-680. https://doi.org/ 10.3168/jds.s0022-0302(80)82989-4.

Canadian Dairy Information Center. 2016. Overview of Canadian dairy industry at the farm. Accessed Jan. 5, 2017. http://www .dairyinfo.gc.ca/index_e.php?s1=dff-fcil\&s2 $=$ farm-ferme\&s3=nb.

Catry, B., J. Dewulf, D. Maes, B. Pardon, B. Callens, M. Vanrobaeys, G. Opsomer, A. de Kruif, and F. Haesebrouck. 2016. Effect of antimicrobial consumption and production type on antibacterial resistance in the bovine respiratory and digestive tract. PLoS One 11:e0146488.

Chelack, B. J., P. Morley, and D. Haines. 1993. Evaluation of methods for dehydration of bovine colostrum for total replacement of normal colostrum in calves. Can. Vet. J. 34:407-412.

Dohoo, I., W. Martin, and H. Stryhn. 2010a. Model-building strategies. Pages 365-394 in Veterinary Epidemiological Research. 2nd ed. VER Inc., Charlottetown, Prince Edward Island, Canada.

Dohoo, I., W. Martin, and H. Stryhn. 2010b. Logistic regression. Pages 395-426 in Veterinary Epidemiological Research. 2nd ed. VER Inc., Charlottetown, Prince Edward Island, Canada.

Donovan, G., I. R. Dohoo, D. M. Montgomery, and F. L. Bennett. 1998. Associations between passive immunity and morbidity and mortality in dairy heifers in Florida, USA. Prev. Vet. Med. 34:3146. https://doi.org/10.1016/s0167-5877(97)00060-3.

Elizondo-Salazar, J., C. Jones, and A. Heinrichs. 2011. Feeding colostrum with an esophageal feeder does not reduce immunoglobulin G absorption in neonatal dairy heifer calves. Prof. Anim. Sci. 27:561564. https://doi.org/10.15232/s1080-7446(15)30539-8.

Faber, S., N. Faber, T. Mccauley, and R. Ax. 2005. Case study: Effects of colostrum ingestion on lactational performance. Prof. Anim. Sci. 21:420-425. https://doi.org/10.15232/s1080-7446(15)31240-7.

Fecteau, G., P. Baillargeon, R. Higgins, J. Pare, and M. Fortin. 2002. Bacterial contamination of colostrum fed to newborn calves in Québec dairy herds. Can. Vet. J. 43:523-527.

Fecteau, G., J. Pare, D. C. Van Metre, B. P. Smith, C. A. Holmberg, W. Gutterbock, and S. Jang. 1997. Use of a clinical sepsis score for predicting bacteremia in neonatal dairy calves on a calf rearing farm. Can. Vet. J. 38:101-104.

Frank, N. A., and J. B. Kaneene. 1993. Management risk factors associated with calf diarrhea in Michigan dairy herds. J. Dairy Sci. 76:1313-1323. https://doi.org/10.3168/jds.s0022-0302(93)77462-7.

Godden, S. 2008. Colostrum management for dairy calves. Vet. Clin. North Am. Food Anim. Pract. 24:19-39. https://doi.org/10.1016/ j.cvfa.2007.10.005.

Godden, S., D. Haines, K. Konkol, and J. Peterson. 2009. Improving passive transfer of immunoglobulins in calves. II: Interaction between feeding method and volume of colostrum fed. J. Dairy Sci. 92:1758-1764. https://doi.org/10.3168/jds.2008-1847.

Gunn, G., C. Heffernan, M. Hall, A. Mcleod, and M. Hovi. 2008. Measuring and comparing constraints to improved biosecurity amongst GB farmers, veterinarians and the auxiliary industries. Prev. Vet. Med. 84:310-323. https://doi.org/10.1016/j.prevetmed .2007.12.003.

Jansen, J., and T. J. Lam. 2012. The role of communication in improving udder health. Vet. Clin. North Am. Food Anim. Pract. 28:363-379. https://doi.org/10.1016/j.cvfa.2012.03.003.

Khan, M., H. Lee, W. Lee, H. Kim, K. Ki, T. Hur, G. Suh, S. Kang, and Y. Choi. 2007. Structural growth, rumen development, and metabolic and immune responses of Holstein male calves fed milk through step-down and conventional methods. J. Dairy Sci. 90:3376-3387. https://doi.org/10.3168/jds.2007-0104.

Lago, A., S. Mcguirk, T. Bennett, N. Cook, and K. Nordlund. 2006. Calf respiratory disease and pen microenvironments in naturally ventilated calf barns in winter. J. Dairy Sci. 89:4014-4025. https:// doi.org/10.3168/jds.s0022-0302(06)72445-6.

Lam, T., J. Jansen, B. V. D. Borne, R. Renes, and H. Hogeveen. 2011. What veterinarians need to know about communication to optimise their role as advisors on udder health in dairy herds. $\mathrm{N}$. Z. Vet. J. 59:8-15. https://doi.org/10.1080/00480169.2011.547163.

Lateur-Rowet, H. J. M., and H. J. Breukink. 1983. The failure of the oesophageal groove reflex, when fluids are given with an oesopha- 
geal feeder to newborn and young calves. Vet. Q. 5:68-74. https:// doi.org/10.1080/01652176.1983.9693874.

McGuirk, S. M. 2008. Disease management of dairy calves and heifers. Vet. Clin. North Am. Food Anim. Pract. 24:139-153. https://doi org/10.1016/j.cvfa.2007.10.003.

McGuirk, S. M., and S. F. Peek. 2014. Timely diagnosis of dairy calf respiratory disease using a standardized scoring system. Anim. Health Res. Rev. 15:145-147. https://doi.org/10.1017/ s1466252314000267.

Mee, J. F. 2004. Managing the dairy cow at calving time. Vet. Clin. North Am. Food Anim. Pract. 20:521-546. https://doi.org/10 .1016/j.cvfa.2004.06.001

Mee, J. F. 2008. Newborn dairy calf management. Vet. Clin. North Am. Food Anim. Pract. 24:1-17. https://doi.org/10.1016/j.cvfa .2007.10.002.

Mormede, P., J. Soissons, R. Raoult, and G. Legarff. 1982. Effect of transportation on blood serum composition, disease incidence and production traits in young calves. Ann. Rech. Vet. 13:369-384.

Ollivett, T. L., D. V. Nydam, T. C. Linden, D. D. Bowman, and M. E. V. Amburgh. 2012. Effect of nutritional plane on health and performance in dairy calves after experimental infection with Cryptosporidium parvum. J. Am. Vet. Med. Assoc. 241:1514-1520. https://doi.org/10.2460/javma.241.11.1514.

Olson, K., B. Cassell, A. Mcallister, and S. Washburn. 2009. Dystocia stillbirth, gestation length, and birth weight in Holstein, Jersey, and reciprocal crosses from a planned experiment. J. Dairy Sci 92:6167-6175. https://doi.org/10.3168/jds.2009-2260.

Panivivat, R., E. Kegley, J. Pennington, D. Kellogg, and S. Krumpelman. 2004. Growth performance and health of dairy calves bedded with different types of materials. J. Dairy Sci. 87:3736-3745. https://doi.org/10.3168/jds.s0022-0302(04)73512-2.

Pardon, B., J. Alliët, R. Boone, S. Roelandt, B. Valgaeren, and P. Deprez. 2015. Prediction of respiratory disease and diarrhea in veal calves based on immunoglobulin levels and the serostatus for respiratory pathogens measured at arrival. Prev. Vet. Med. 120:169-176. https://doi.org/10.1016/j.prevetmed.2015.04.009.

Pardon, B., K. D. Bleecker, M. Hostens, J. Callens, J. Dewulf, and P. Deprez. 2012a. Longitudinal study on morbidity and mortality in white veal calves in Belgium. BMC Vet. Res. 8:26. https://doi.org/ 10.1186/1746-6148-8-26.

Pardon, B., B. Catry, J. Dewulf, D. Persoons, M. Hostens, K. De Bleecker, and P. Deprez. 2012b. Prospective study on quantitative and qualitative antimicrobial and anti-inflammatory drug use in white veal calves. J. Antimicrob. Chemother. 67:1027-1038. https://doi.org/10.1093/jac/dkr570.

Pardon, B., K. De Bleecker, M. Hostens, J. Callens, J. Dewulf, and P. Deprez. 2014. Characteristics and challenges of the modern Belgian veal industry. Vlaams Diergen. Tijds. 83:155-163.

Postema, H. J., and J. Mol. 1984. Risk of disease in veal calves: Relationships between colostrum-management, serum immunoglobulin levels and risk of disease. Zentralbl. Veterinarmed. A 31:751-762. https://doi.org/10.1111/j.1439-0442.1984.tb01334.x.

Renaud, D. L., T. F. Duffield, S. J. LeBlanc, D. B. Haley, and D. F. Kelton. 2017. Management practices for male calves on Canadian dairy farms. J. Dairy Sci. 100:6862-6871. https://doi.org/10.3168/ jds.2017-12750.

Ritter, C., G. Kwong, R. Wolf, C. Pickel, M. Slomp, J. Flaig, S. Mason, C. Adams, D. Kelton, J. Jansen, J. D. Buck, and H. Barkema. 2015. Factors associated with participation of Alberta dairy farmers in a voluntary, management-based Johne's disease control program. J. Dairy Sci. 98:7831-7845. https://doi.org/10.3168/jds $.2015-9789$

Robison, J., G. Stott, and S. Denise. 1988. Effects of passive immunity on growth and survival in the dairy heifer. J. Dairy Sci. 71:12831287. https://doi.org/10.3168/jds.s0022-0302(88)79684-8.
Sargeant, J. M., T. E. Blackwell, S. W. Martin, and R. R. Tremblay 1994. Production practices, calf health and mortality on six white veal farms in Ontario. Can. J. Vet. Res. 58:189-195.

Schuijt, G., and M. Taverne. 1994. The interval between birth and sternal recumbency as an objective measure of the vitality of newborn calves. Vet. Rec. 135:111-115. https://doi.org/10.1136/vr .135.5.111.

Shively, C. B., N. Urie, and J. E. Lombard. 2016. Management of dairy bull calves on U.S. dairy operations. J. Anim. Sci. 94:581. https:// doi.org/10.2527/jam2016-1210.

Smith, G. W., and D. M. Foster. 2007. Short communication: Absorption of protein and immunoglobulin $\mathrm{G}$ in calves fed a colostrum replacer. J. Dairy Sci. 90:2905-2908.

Spooner, J. M., C. A. Schuppli, and D. Fraser. 2014. Attitudes of Canadian citizens toward farm animal welfare: A qualitative study. Livest. Sci. 163:150-158.

Swan, H., S. Godden, R. Bey, S. Wells, J. Fetrow, and H. ChesterJones. 2007. Passive transfer of immunoglobulin $\mathrm{G}$ and preweaning health in Holstein calves fed a commercial colostrum replacer. J. Dairy Sci. 90:3857-3866. https://doi.org/10.3168/jds.2007-0152.

Todd, C., K. Leslie, S. Millman, V. Bielmann, N. Anderson, J. Sargeant, and T. Devries. 2017. Clinical trial on the effects of a free-access acidified milk replacer feeding program on the health and growth of dairy replacement heifers and veal calves. J. Dairy Sci. 100:713-725. https://doi.org/10.3168/jds.2016-11401.

van der Fels-Klerx, H., H. Horst, and A. Dijkhuizen. 2000. Risk factors for bovine respiratory disease in dairy youngstock in The Netherlands: The perception of experts. Livest. Prod. Sci. 66:35-46. https://doi.org/10.1016/S0301-6226(00)00163-9.

Vanhonacker, F., W. Verbeke, E. Van Poucke, and F. Tuyttens. 2008. Do citizens and farmers interpret the concept of farm animal welfare differently? Livest. Sci. 116:126-136. https://doi.org/10.1016/ j.livsci.2007.09.017.

Vasseur, E., J. Rushen, A. D. Passillé, D. Lefebvre, and D. Pellerin. 2010. An advisory tool to improve management practices affecting calf and heifer welfare on dairy farms. J. Dairy Sci. 93:4414-4426. https://doi.org/10.3168/jds.2009-2586.

Virtala, A.-M., G. Mechor, Y. Gröhn, and H. Erb. 1996. The effect of calfhood diseases on growth of female dairy calves during the first 3 months of life in New York State. J. Dairy Sci. 79:1040-1049. https://doi.org/10.3168/jds.s0022-0302(96)76457-3.

Waltner-Toews, D., S. Martin, and A. Meek. 1986. Dairy calf management, morbidity and mortality in Ontario Holstein herds. IV. Association of management with mortality. Prev. Vet. Med. 4:159 171. https://doi.org/10.1016/0167-5877(86)90020-6.

Wells, S. J., D. A. Dargatz, and S. L. Ott. 1996. Factors associated with mortality to 21 days of life in dairy heifers in the United States. Prev. Vet. Med. 29:9-19. https://doi.org/10.1016/S0167 -5877(96)01061-6.

Wilson, L., J. Smith, D. Smith, D. Swanson, T. Drake, D. Wolfgang, and E. Wheeler. 2000. Characteristics of veal calves upon arrival, at 28 and 84 days, and at end of the production cycle. J. Dairy Sci. 83:843-854. https://doi.org/10.3168/jds.s0022-0302(00)74948-4.

Winder, C. B., D. F. Kelton, and T. F. Duffield. 2016. Mortality risk factors for calves entering a multi-location white veal farm in Ontario, Canada. J. Dairy Sci. 99:10174-10181. https://doi.org/10 $.3168 / j d s .2016-11345$.

Windeyer, M., K. Leslie, S. Godden, D. Hodgins, K. Lissemore, and S. LeBlanc. 2014. Factors associated with morbidity, mortality, and growth of dairy heifer calves up to 3 months of age. Prev. Vet. Med. 113:231-240. https://doi.org/10.1016/j.prevetmed.2013 .10.019. 